\title{
Mecanismos de emotividade em relatos de violência: estratégias de elicitação-empática e de (re) enquadre sociocomunicativo
}

\author{
Emotivity mechanisms in reports of violence: strategies of \\ empathic elicitation and of social communication (re)framing
}

Kaline Girão Jamison

Universidade da Integração Internacional da Lusofonia Afro-brasileira - UNILAB

\begin{abstract}
Resumo: Nesse trabalho buscamos analisar, - na dinâmica da interação entre duas mulheres em situação de violência e escrivãs, na ocasião dos registros de boletins de ocorrência (BO) em uma Delegacia Especializada em Atendimento à Mulher (DEAM) de Fortaleza, as categorias emotivas propostas por Caffi e Janney (1994) avaliatividade, proximidade, especificidade, evidencialidade e volicionalidade -, investigando a relação entre esses mecanismos emotivocomunicativos e seu papel como estratégia de elicitação empática (MARTINOVSKY; MAO, 2009), como também de elaboração de faces (GOFFMAN, 1967). O objetivo consiste, portanto, em examinar a comunicação emotiva, num contexto de relato de violência, e sua relação com processos de (re)enquadre (frame) sociocomuniticativo em conversas autênticas entre mulheres. Constatamos que é a partir da noção de enquadramento (frame) que a situação interacional se organiza e que os papéis sociais são definidos. No caso das mulheres que se dirigiram à DEAM para realizar o $\mathrm{BO}$, cada uma reivindica uma imagem social apropriada para as regras da interação comunicativa da qual fazem parte. Por exemplo, no caso das duas participantes que não desejaram requerer medidas legais contra seus agressores, apenas registrar a queixa, detectamos que elas se utilizaram de categorias emotivas no intuito de conquistarem a empatia da interlocutora e estabelecer uma maior adequação a seu enquadre sociocomunicativo.
\end{abstract}

Palavras-chave: Mecanismos de emotividade. Elaboração de Faces. Empatia. Interação.

Abstract: In this work, we sought to analyze the dynamics of the interaction between two women in situations of violence and female police agents, at the time of police report registration at a Police Department Specialized for Women in Fortaleza, the emotive categories proposed by Caffi and Janney (1994) - evaluation, proximity, specificity, evidentiary and volitionality -, and to investigate the relationship between these emotivocommunicative mechanisms and their role as empathic elicitation strategy (MARTINOVSKY; MAO, 2009 ; 1967). The aim is, therefore, to examine emotional communication in a context of violence and its relationship with the processes of sociocommunication (re)framing in authentic conversations among women. We saw that it is from the notion of framing that the interactional situation is organized and that social roles are defined. In the case of women who went to perform the police report, each one claims an appropriate social image to the rules of the communicative interaction, which they are part of. For example, in the case of the two participants who did not wish to request legal action against their aggressors, only to register the complaint, we detected that they used emotional categories in order to gain the empathy of the interlocutor and to establish a greater adequacy to their sociocommunication framework.

Keywords: Emotive mechanisms. Face work. Empathy. Interaction. 


\section{Introdução}

Com o propósito de compreender o fenômeno da empatia e suas formas de manifestação na linguagem, nosso trabalho tem como objetivo, verificar, em dois momentos de interação discursiva entre mulheres em situação de violência (daqui em diante, MSV) e escrivãs, durante a confecção de boletins de ocorrência (doravante, $\mathrm{BO}$ ) em uma Delegacia de Atendimento Especializado à Mulher (DEAM) de Fortaleza, se os dispositivos emotivos da comunicação influenciam no desenvolvimento de movimentos de empatia e nos processos de (re) enquadre sociocomunicativo.

Embora a lei 11. 340, mais conhecida como Lei Maria da Penha, tenha favorecido a defesa da integridade física e psicológica das mulheres e dado a elas a chance de romperem com o silêncio contra todas as formas de violência, nem sempre elas mantém as denúncias feitas contra os agressores com quem têm ou tiveram relação afetiva. Infelizmente, conforme declara um promotor de justiça de Teresina, "de cada dez mulheres que denunciam, sete retiram as queixas" (PEDROSA, 2011).

Acreditamos, portanto, que por ser um tema complexo, o estudo da violência conjugal deve levar em consideração os discursos dessas mulheres, a fim de obter insights mais ricos também sobre indícios empáticos na linguagem (MARTINOVSKI, 2006) e sobre estratégias de atenuação do dizer, às quais relacionamos as ações de (re)enquadramento sociocomunicativo (GOFFMAN, 1967).

E assim como Martinovski (2006), também utilizamos as funções de empatia numa perspectiva discursiva, mas para entendermos melhor o processo de construção de sentimentos empáticos em situações de interação, decidimos lançar um olhar sobre a forma como as participantes negociam suas imagens sociais nas situações comunicativas de registros de boletins de ocorrência (BO).

Nesse sentido, visamos analisar duas interações de registro de $\mathrm{BO}$ de mulheres que não demonstraram interesse em requerer as medidas protetivas contra seu agressores, apesar de ambas já terem registrado queixa contra os mesmos homens anteriormente.

Buscamos, portanto, responder à seguintes perguntas de pesquisa: 1) em que medida os dispositivos emotivos da comunicação se relacionam aos mecanismos de (re)enquadramento sociocomunicativo (trabalhos de elaboração de face) e a ações de elicitação empática nos discursos de duas escrivãs e de duas MSV (que não quiseram requerer medidas protetivas contra seus agressores) durante o registro de BOs em uma DEAM de Fortaleza?; 2) quais são os dispositivos emotivos mais utilizados para regular a atenuação da fala das MSV e elicitar empatia às escrivãs?

\section{2 (Re)Enquadre sociocomunicativo de MSV: adequando a imagem social aos objetivos comunicativos}

Vivemos num mundo de encontros sociais que envolvem o contato face a face com outras pessoas, que também participam de grupos sociais, desempenham funções sociais, estabelecidas a partir da relação com os outros membros da mesma sociedade. Nesse mesmo viés, Goffman (1985) mostra que os indivíduos sociais esperam que suas características sociais sejam respeitadas, acreditadas e valorizadas adequadamente. Por outro lado, em nossa sociedade contemporânea ocidental, esses papéis são dotados de dinamismo e flexibilidade, exigindo de nós condutas adequadas, as quais nem sempre são possíveis manter (PRETI, 2004).

Logo, é necessário a regulagem da construção da imagem que uma pessoa precisa assumir em determinados papeis sociais. Nesse sentido, Villaça e Bentes (2008) argumentam que, quando se entra em contato com outra pessoa, existe a preocupação de preservar a autoimagem pública e em uma interação, é possível que essa imagem não se concretize ou seja afetada por incidentes do contexto interacional.

A ideia de "apresentação de si" e de construção de uma autoimagem favorável e que convença os participantes da interação verbal está de 
acordo com o que foi apresentado por Tracy e Coupland (1991) sobre a inter-relação entre objetivo comunicativo e discurso. Para os autores, os objetivos e intenções comunicativas são estabelecidos, ou fortemente guiados, pela natureza da situação social, cuja dinâmica interacional não é apenas um jogo de imagens sociais a serem mantidas, ou ameaçadas, mas como um palco, onde imagens sociais, estratégias e intenções comunicativas contracenam juntas.

Goffman (2011) define face como "um valor social positivo que uma pessoa efetivamente reivindica para si mesma através da linha que os outros pressupõem que a pessoa assumiu durante um contato particular" (p. 13). E descreve "linha" como aos padrões verbais ou não verbais adotados pelo ator da ação para mostrar sua versão da situação, dos outros e de si mesmo, podendo ser intencional ou não.

Quando a face de uma pessoa não está alinhada com as evidências apresentadas ou são internamente inconsistentes, é dito que a pessoa está com a face errada. Nesse caso, quando as contribuições da pessoa não conseguem ser "costuradas" à ocasião, sua face poderá ser ameaçada "fazendo com que ela se sinta, possivelmente, envergonhada, ou inferior" (GOFFMAN, 2011, p. 16).

No caso das MSV conjugal que comparecem à DEAM para fazer o $\mathrm{BO}$, a linha mantida por elas é do tipo institucionalizado legítimo (GOFFMAN, 2011, p. 15), pois durante a interação, seus atributos são conhecidos e se pode esperar que ela seja apoiada na face assumida, de alguém que sofre maus tratos. Assim, é esperado que a linha assumida pela MSV que procurou uma delegacia seja compatível à natureza desse encontro, no qual espera dela a face de alguém que está decidida a acabar com a violência sofrida e a pedir ajuda da polícia.

Assim, é necessário lançarmos mão do conceito enquadramento (GOFFMAN, 1986), que se refere à experiência dos sujeitos no mundo, aos princípios de organização que governam os eventos sociais e nosso envolvimento com eles.
Em outros termos, para o autor, cada ser social emprega a estrutura de sua experiência individual e um conjunto de outros elementos para decodificar e entender os momentos de suas vidas sociais. Caso esses eventos sejam decodificados de forma mais direta, por conterem estruturas mais apresentáveis, permitindo ao usuário percebê-las e decodificá-las, podem ser chamados, segundo Goffman (1985), de esquemas primários.

Nesse sentido, atribuímos ao momento de confecção de boletins de ocorrência em uma DEAM, na cidade de Fortaleza, um caráter de esquema primário, pois apresenta uma estrutura socialmente constituída e que serve como pano de fundo para a compreensão dos eventos que o constituem. Nesse sentido, o momento de confecção de BO pode ser considerado um esquema primário, pois regula a conduta dos participantes e principalmente, a imagem social apropriada para esse evento. Logo, requer um gerenciamento de consequências por parte dos atores sociais, ou seja, o implemento de fazeres guiados, regras de conduta, os quais também sofrem influência da motivação e intenção comunicativa.

Nesse prisma, a MSV tem a "obrigação" de fazer qualquer tipo de relato que ameace a face de seu agressor, pois, caso não o faça, estará comprometendo sua autoimagem.

\section{Funções da empatia na interação}

De acordo com Martinovski e Mao (2009), a emergência da empatia ou a falta dela representa uma das características de qualquer situação interativa. De acordo com esses autores, a empatia tem diferentes funções no discurso, podendo ser experienciada, doada, elicitada, aceita, rejeitada ou recusada. No contexto desse trabalho, focalizamos apenas nas duas seguintes funções da empatia no discurso:

1. elicitação: quando na comunicação um dos participantes avalia e sente a necessidade de elicitar empatia ao outro (A elicita empatia de B se A deseja que B sinta empatia por B);

2. doação: quando na interação há uma reorganização e reavaliação temporária ou 
permanente dos objetivos interacionais em benefício do outro ( $A$ dá empatia a $B$ se $A$ entende/sente o que B sente).

Desse modo, concebemos que o processo da empatia se constitui de passos e de momentos empáticos e que, por meio de uma observação baseada no discurso e em sua dinâmica, é possível verificar o uso sistemático de mecanismos linguísticos que funcionam como elicitadores empáticos, os quais podem promover movimentos de doação ou rejeição empática.

No entanto, como instrumento de análise da emergência de indícios empáticos no contexto desse estudo, que chamamos de movimentos de empatia, optamos em adotar os dispositivos emotivos, sobre os quais tratamos a seguir.

\section{Emotividade e suas manifestações no discurso}

No que tange aos estudos sobre emoção e linguagem, Bednarek (2008) observa que o interesse, nessa perspectiva, é recente, não havendo nenhuma teoria unificada sobre emoção ou afeto com a linguagem, apenas abordagens discrepantes e amplas sobre a expressão emotiva de modo geral. A autora remete essa lacuna à complexidade da forma com que expressamos emoções: podemos expressar o que não sentimos, podemos sentir algo e não expressarmos, expressarmos algo de forma consciente, inconsciente, intencional ou não.

De todo modo, Caffi e Janney (1994, p. 326) defendem que "emoções e linguagem estão intimamente interconectados à fala e à escrita". Nessa perspectiva, Caffi e Janney (1994) propõem uma abordagem denominada pragmática da comunicação emotiva. Com o objetivo de estabelecer uma conexão entre as abordagens psicológica e linguística, os autores propõem seis dispositivos emotivos diferentes, cujo foco não está apenas no conteúdo proposicional das unidades de análise (nos níveis semânticos e lexicais), mas também em ressaltar o fenômeno emotivo da comunicação de modo mais globalizado. Assim, organizaram, de forma sistemática, diferentes tipos do que chamaram de "dispositivos estruturantes", "indicadores", ou "marcadores", que são baseados nos aspectos retóricos, estilísticos, prosódicos e paralinguísticos usados pelos falantes para produzirem diferentes efeitos emotivos e que estão conectados aos tipos de instâncias emotivas que os falantes desejam revelar. São eles:

1. dispositivos emotivos de avaliatividade (distinção central: positivo/negativo): essa categoria "inclui todos os tipos de escolhas verbais e não verbais que sugerem avaliação positiva ou negativa por parte do falante em relação a um tópico, interlocutor, ou interlocutores no discurso (p. ex. "Você é péssimo/o melhor" - menor/maior avaliatividade);

2. dispositivos emotivos de proximidade (distinção central: próximo/distante): incluem todos os tipos de escolhas verbais e não verbais que variam as distâncias metafóricas entre: os falantes e o conteúdo de seu enunciado e entre os falantes e seus interlocutores. Essa categoria subdivide-se em: 2.1) marcadores de proximidade espacial: regulam distâncias metafóricas entre eventos interiores e exteriores expressados pelos falantes. Por exemplo, o uso de pronomes demonstrativos: (por ex., "Essa/aquela mentira doeu em mim" - maior/menor proximidade espacial); 2.2) marcadores de proximidade temporal regulam distâncias metafóricas entre "eventos presentes e não-presentes" (CAFFI, 2007, p. 142). Ou seja, distâncias que dizem respeito ao tempo interno ou real (por ex., "Eu fiquei/estou muito envergonhada com tudo que the disse" menor/maior proximidade espacial); 2.3) marcadores de proximidade social regulam as distâncias pessoais e interpessoais (por ex., "Senhora/Mulher, ele sempre me bate quando ele bebe" - menor/maior proximidade social); 2.4) marcadores de proximidade de ordem seletiva, definidos na literatura como "ordem de referência" ou "topicalização", que servem para regular as distâncias de conceitos nos discursos e diz respeito a um dado referente no enunciado (por ex., "A mulher apanhou do marido" / "O marido 
bateu na mulher" - menor/maior proximidade do status do agente da ação);

3. dispositivos emotivos de especificidade: (distinção central: clareza/vaguidade) essa categoria inclui os dispositivos linguísticos usados para variar a precisão, acurácia ou menção sobre tópicos, partes de tópicos, o $\mathrm{Eu}$ do falante, ou interlocutores do discurso. (por ex., "O jantar/bife estava ótimo (menor/maior especificidade); Alguém/você pode me ajudar? (menor/maior especificidade);

4. dispositivos emotivos de evidencialidade: (distinção central: clareza/vaguidade) são as escolhas que regulam aspectos possíveis de serem inferidos sobre: atenuação, confiabilidade, autoridade, validade, ou valor de verdade do que está sendo expressado, sugerem confiança ou dúvida em relação à informação, que podem ser dos tipos: julgamento (pode estar/está); intenções (talvez volte/ irei voltar); comprometimento com as proposições por meio da modalidade epistêmica: (acho que sei/ sei); advérbios modais (possivelmente/certamente);

5. dispositivos emotivos de volicionalidade: (distinção central: autoassertividade/não assertividade): escolhas linguísticas, ou estratégias discursivas para variar os níveis de autoassertividade diante dos interlocutores e todas as escolhas usadas para lançar os próprios falantes ou os interlocutores em papéis discursivos ativos ou passivos. É inferida no discurso por meio do uso de, por ex., voz ativa ou voz passiva (decidi/foi decidido), o uso de modais em pedidos (passa o sal/pode passar o sal?), escolha do uso de agentes da ação ou pronomes (quero/você quer ir embora?);

6. dispositivos emotivos de quantificação (distinção central: mais/menos): inclui as escolhas de quantificação, graus, medidas, duração, ou quantidade de um dado fenômeno linguístico, que pode ser quase de qualquer tipo: intensidade de uma atividade, duração de uma performance, quantificação de um objeto, intensidade de um advérbio (extremamente quente), uso de pronomes relativos como intensificadores (Que dia longo!), adjetivos de ênfase (completa/total catástrofe), Além disso, fenômenos fonológicos, como alongamento de vogais ( é eno:::rme); realce prosódico, como aumento do tom de voz (Eu NÃO vou!), escolhas estilísticas de repetição (estamos muito, muito felizes.)

\section{Procedimentos metodológicos}

Adotamos a Análise da Conversação, que é utilizada para verificar modos de análises das trocas verbais autênticas e para responder a questões de como as pessoas criam e resolvem conflitos interacionais. Assim, nossa pesquisa, de caráter exploratório-descritivo, apoia-se em dados baseados em uso autêntico, coletados por observação nãoparticipante, e utiliza procedimentos de campo com mulheres que se dirigiram à Delegacia Especializada em Atendimento à Mulher de Fortaleza (DEAM) para prestar queixa contra seus maridos / (ex)companheiros por violência conjugal.

Ressaltamos que os dados para esse estudo constituem um recorte de nossa tese de Doutorado (JAMISON, 2015), na qual realizamos a análise de quatro interações, ao invés de duas.

Para essa análise, lançamos um olhar mais cuidadoso sobre os dispositvos emotivos contidos nos trechos destacados. Escolhemos examinar alguns excertos das transcrições feitas a partir das declarações de duas mulheres que não desejaram requerer medidas legais contra seus agressores, mesmo já tendo procurado a polícia no passado para prestar queixa contra os mesmos agressores. Elas são identificadas nos excertos e no corpo do trabalho como MSV1 e MSV2 (mulher em situação de violência), enquanto que as escrivãs são representadas por E1 e E2.

A primeira participante MSV1, uma de mulher de 39 anos, havia saído de casa por causa de conflitos com o ex-companheiro, e, na ocasião, todos os seus pertences tinham ficado na casa onde atualmente continua residindo o seu ex-companheiro, com quem viveu maritalmente por quase 8 anos. Procurou a DEAM para reaver seus pertences.

Já a segunda declarante é uma senhora de 45 anos, mãe de duas filhas adultas, cujo ex- 
companheiro "come, bebe e dorme" na casa da exmulher, sem demonstrar constrangimento, mesmo eles estando separados há mais de quatro anos. Sua queixa é que o ex-companheiro não apenas frequenta a casa dela, e a ida de MSV2 à DEAM tem como objetivo pedir ajuda à polícia para afastá-lo de sua residência.

Como nosso foco é a linguagem autêntica em uso, as análises baseiam-se necessariamente na produção dos interlocutores, assim, registramos e transcrevemos os dados orais com precisão.

Adotamos a proposta de unidades de entonação (CAMERON; MASLEN, 2010), que são marcadas por pausas, e por uma mudança no contorno da entonação na última sílaba.

A seguir, as convenções que utilizamos nas transcrições de nosso corpus.

Quadro 1: Convenções de transcrição

\begin{tabular}{|ll|}
\hline$:$ & alongamento de vogal pequeno \\
$: \because$ & alongamento de vogal médio \\
$: \because$ & alongamento de vogal grande \\
$\ldots(2.0)$ & pausa maior do que dois segundos \\
{[]} & sobreposição de discursos \\
- & silabação \\
$\rightarrow$ & assalto ao turno \\
- & unidade truncada \\
, & contorno de entonação que continua \\
& contorno de entonação finalizada \\
CAIXA ALTA aumento de voz, ênfase \\
$(())$ & observações da pesquisadora \\
\hline
\end{tabular}

Fonte: Adaptado pela autora a partir de Cameron (2011, p. XV) e de Du Bois et al. (1993).

Após transcrita, a conversação foi ouvida novamente para que ajustes pudessem ser feitos aos códigos já inseridos. Após isso, demos início às análises, cujos passos estão sumarizados a seguir.

1- Relemos e selecionamos os trechos dos relatos que pudessem conter mais elementos emotivos. Foram selecionados 7 excertos: 3 retirados dos diálogos entre E1 e MSV1 e 3, da conversa entre E2 e MSV2.

2- Detectamos as ocorrências de indícios empáticos e de trabalhos de faces. Essas palavras, ou expressões, foram sublinhadas e codificadas para receber destaque e serem relacionadas aos códigos que as procediam.

3- Identificamos os dispositivos emotivos (palavra ou expressão) que davam suporte às ações atenuadoras e de proteção de face com negrito e os codificamos nos excertos.

Para realizarmos as análises, utilizamos os seguintes códigos:

Quadro 2: Códigos usados nas análises

Fonte: Retirado de Jamison (2015, p. 85)

\begin{tabular}{|c|c|}
\hline $\begin{array}{l}\text { Códigos dos dispositivos } \\
\text { emotivos de } \\
\text { comunicaçãoutilizados }\end{array}$ & O que significam \\
\hline$[\mathrm{AVA}-] /[\mathrm{AVA}+]$ & $\begin{array}{l}\text { Dispositivo emotivo de menor } \\
\text { ou maior avaliatividade }\end{array}$ \\
\hline$[\mathrm{EVI}-] /[\mathrm{EVI}+]$ & $\begin{array}{l}\text { Dispositivo emotivo de menor } \\
\text { ou maior evidencialidade }\end{array}$ \\
\hline$[\mathrm{ESP}-] /[\mathrm{ESP}+]$ & $\begin{array}{l}\text { Dispositivo emotivo de menor } \\
\text { ou maior especificidade }\end{array}$ \\
\hline$[\mathrm{PROX}-] /[\mathrm{PROX}+]$ & $\begin{array}{l}\text { Dispositivo emotivo de menor } \\
\text { ou maior proximidade }\end{array}$ \\
\hline [QUA-]/[QUA+] & $\begin{array}{l}\text { Dispositivo emotivo de menor } \\
\text { ou maior quantificação }\end{array}$ \\
\hline [VOL-]/[VOL+] & $\begin{array}{l}\text { Dispositivo emotivo de menor } \\
\text { ou maior volitividade }\end{array}$ \\
\hline $\begin{array}{l}\text { Códigos das ações de } \\
\text { elaboração de faces }\end{array}$ & O que significam \\
\hline$[\mathrm{FC}: \mathrm{PPF}]$ & $\begin{array}{l}\text { Trabalho de preservação da } \\
\text { própria face }\end{array}$ \\
\hline [FC:PFO] & $\begin{array}{l}\text { Trabalho de preservação da } \\
\text { face do outro }\end{array}$ \\
\hline$[\mathrm{FC}: \mathrm{AmF}]$ & $\begin{array}{l}\text { Trabalho de ameaça à face do } \\
\text { interlocutor }\end{array}$ \\
\hline [FC:AmFO] & $\begin{array}{l}\text { Trabalho de ameaça à face do } \\
\text { outro (agressor) }\end{array}$ \\
\hline [FC:AtOf] & $\begin{array}{l}\text { Manifestação de atenuação de } \\
\text { ofensa }\end{array}$ \\
\hline $\begin{array}{l}\text { Códigos de função de } \\
\text { empatia }\end{array}$ & O que significam \\
\hline [EMP:EL] & Ação de elicitação empática \\
\hline$[\mathrm{EMP}: \mathrm{R}+]$ & $\begin{array}{l}\text { Ação de resposta empática } \\
\text { favorável }\end{array}$ \\
\hline [EMP:R-] & $\begin{array}{l}\text { Ação de resposta empática } \\
\text { desfavorável }\end{array}$ \\
\hline [EMP:AC] & $\begin{array}{l}\text { Ação de aceitação da empatia } \\
\text { doada }\end{array}$ \\
\hline [EMP:D] & Ação de doação empática \\
\hline
\end{tabular}

Fonte: Retirado de Jamison (2015) 
Frisamos que a organização do corpus completo (JAMISON, 2015), assim como a numeração das linhas e codificação das ocorrências, foram realizadas no processador de texto Word. Por se tratarem de recortes, os excertos apresentados nesse trabalho indicam numerações de linhas que não obedecem uma ordem numérica.

Quando mencionamos as linhas dos excertos nas análises, utilizamos parênteses com a indicação do número ao qual a(s) linha(s) se refere $(\mathrm{m})$. Caso fossem linhas alternadas, elas eram separadas por vírgulas (p. ex: I. 3, 6), mas caso a análise fizesse referência a linhas contínuas, essas eram separadas por um travessão (p. ex: I. 4-6).

\section{Análise e discussão dos dados}

Nesta parte do trabalho, apresentamos as análises realizadas a partir das transcrições dos diálogos entre escrivãs e MSV. Aqui, lançamos um olhar mais cuidadoso sobre de duas interações comunicativas de registros de $\mathrm{BO}$.

Em cada excerto, identificamos dois dispositivos emotivos da comunicação, nos processos de (re)enquadramento sociocomunicativo e nos movimentos empáticos em cada interação.

\subsection{A interação de MSV1 com E1}

De fala compassada, MSV1 mostra-se em prejuízo pela falta de seus instrumentos de trabalho, ratificando, assim, a face de vítima que precisa da ajuda da polícia. Durante quase toda a interação, procura manter essa imagem enquanto usa medidas de prevenção de própria face e dispositivos de emotividade.

$\mathrm{Na}$ primeira fase dessa interação, percebemos que a escrivã (E1) busca realizar a identificação do agressor:

\footnotetext{
1. E1: É contra quem?

$2 . \quad$.... o boletim?

3. MSV1: É porque eu convivi com uma pessoa [ESP-] 7 anos,
}
4.
5. ...aí a gente tamo com oito:
6. dias de separado aí eu::
... eu queria [VOL-] assim,
[EVI-]
7.
.. pra eu pegar as minhas coisas de trabalho
8.
.. Porque eu sou costureira [ESP+]
9.
...e eu não tenho

condições [VOL+] de comprar outra máquina [Emp:EL]

$\begin{array}{ll}10 . & \text { Aí:: } \\ 11 . & \ldots \text { eu queria [VOL-] tirar } \\ 12 . & \text { minha-minhas roupas } \\ 13 . & \text {... minhas- } \quad \text { [EVI-] }\end{array}$

\section{4. $E: \quad \rightarrow$ E ele não deixa $[E S P+]$ você tirar? [Emp:R+]}

Quando MSV1 se refere ao agressor como "uma pessoa", um atenuador do tipo dispositivo de especificidade é utilizado como forma de demonstrar ao ouvinte uma "distância emotiva ou cognitiva" (CAFFI, 2007, p. 129), o que assegura a face a ser mantida por MSV1.

Em seguida, há indicadores de pouca autoassertividade $(1.6,11)$ quando MSV1 diz que "queria", o que representa pouca volicionalidade e demonstra falta de autoridade e assertividade, ao formular seu pedido à agente policial. Verificamos ainda uma postura de insegurança em relação ao tópico discursivo, quando o dispositivo de baixa evidencialidade, talvez provocado pela vontade de preservar seu território pessoal, identificado pelo anacoluto e repetição lexical (I.13).

Ao mesmo tempo em que apresenta um discurso fragmentado por indicadores emotivos de pouca assertividade para construir uma imagem de fragilidade, MSV1 usa elementos de mais autoassertividade (I.9) e mais específicos (I.8) ("sou costureira" e "não tenho condições") com a função, possivelmente, de abreviar seu relato e elicitar empatia de sua interlocutora, a qual responde 
positivamente por meio de um assalto de turno no sentido de busca de mais clareza sobre o tópico.

Em seguida, a escrivã busca uma descrição dos eventos violentos aos quais MSV1 foi submetida, cuja atitude aparenta ser de proteção de sua própria face, sendo evasiva e recusando, sutilmente, detalhar o que houve (I. 24-43):

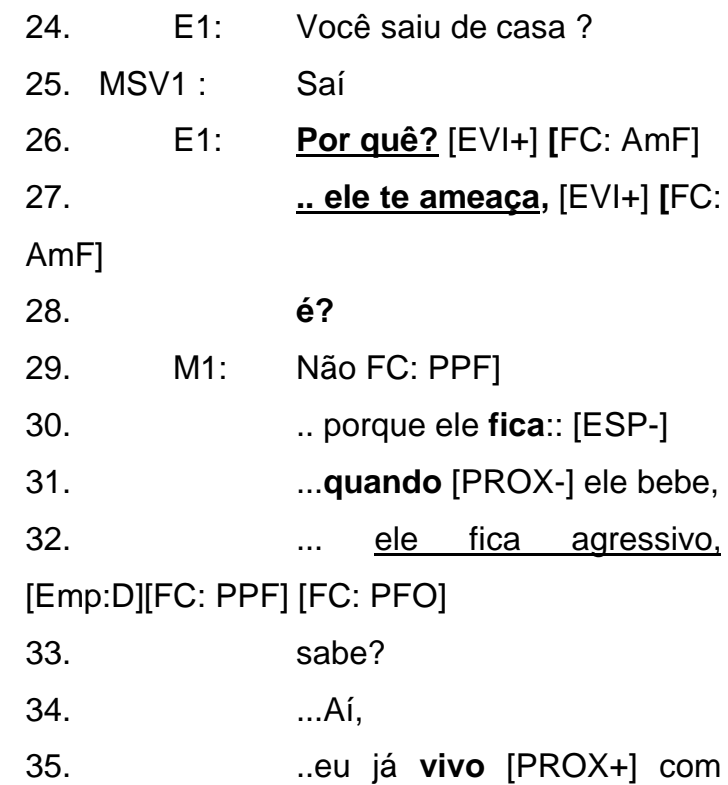
ele há 7 anos a gente sempre-
36. $\mathrm{E} 1: \quad \rightarrow$ E ele te ameaçava? $[\mathrm{EVI}+][\mathrm{FC}: \mathrm{AmF}]$

37.

... te agredia? $[E V I+][F C:$

$\mathrm{AmF}]$

38. MSV1 :

Não, $[E V I+][F C: P P F]$

39.

..Aquelas [PROX-] coisas

[ESP-] de::

40.

de sempre né? [ESP-]

[Emp:EL]

41.

De tá discutindo [AVA-],

Nesse trecho (I. 24-42), MSV1 indicia ter sua face ameaçada quando E1 insiste em obter mais informações sobre as agressões sofridas (I. 26,27), de forma assertiva e por meio de dispositivos de maior evidencialidade. E como forma de preservar diretamente, não apenas a sua face, mas a do agressor, lança mão de um dispositivo de menor especificidade ("fica agressivo" ao invés de "é agressivo"), além de usar um de menor proximidade temporal, "quando", (I. 31), pois cria uma distância do fato da agressão, modalizando a ação do agressor.
Essa passagem indicia uma demonstração de empatia em relação ao acusado e uma ação de proteção a sua própria face e à dele, pois justifica suas ações, que estão sujeitas, segundo MSV1, ao efeito do álcool.

Embora permaneça tentando proteger sua face e a do seu ex-companheiro, ao reivindicar seu território pessoal, E1, que ocupa um espaço determinado por esquemas contextuais antecipatórios (CAFFI, 2007), os quais a encarregam de conduzir a sequencialidade do tópico e de obter todas as informações necessárias para o registro da queixa crime, dá prosseguimento às perguntas, com marcas de maior evidencialidade $(1.36,37)$, as quais ocasionam uma ameaça à face de MSV1 (I. 36-37).

Mais uma vez, para evitar aproximação e atenuar suas revelações, vemos o uso de um marcador de menor proximidade espacial ("aquelas") e outro de menor nível de especificidade ("coisas"). 0 enunciado "de tá discutindo" (I. 41) revela ainda outro atenuador de especificidade, pois, ao omitir o sujeito da oração, provoca indeterminação, aumentando o nível de vagueza e assinalando um afastamento. Também, representa uma proposição de menor avaliatividade, pois não nos remete, necessariamente, a um momento violento, o que mostra uma ação de proteção de face e dá indícios de doação empática ao agressor.

No excerto seguinte, MSV1 é questionada se já havia feito outro BO contra o mesmo acusado, a qual admite que sim, mas demonstrando uma evidente dificuldade de processamento cognitivo e formulação textual (demonstradas pelas pausas, hesitações e repetições), da linha 134 à 136 . Esses atenuadores podem ser observados a partir do emprego de modulações de menor evidencialidade (I. 13, 135). Ao mesmo tempo, verificamos também o uso do dispositivo "lá", o que denota uma marcador de menor proximidade, o que nos ajuda a inferir sua intenção em abrandar a revelação de que as agressões sofridas são reincidentes.

132. E1: É o primeiro boletim é ?
133.


134. MSV1: Foi:: [EVI-]

135. ... eu -eu [EVI-] fiz esse aqui mas já tá com:: [EVI-]

136. $\quad \ldots$ Foi lá [PROX-] na delegacia da Parangaba:: ((entrega boletim à E1)) 137. E1: Humm. ((lê boletim)) 138. $\quad \ldots . . E$ você nem fez exame de corpo e delito né? [FC: AmF]

139. MSV1 Não,

140.

141. ... A gente [ESP-][VOL-] tem

pena né? [ESP-] [Emp:EL]

142. Que a pessoa [ESP-] seja

presa? [Emp:EL] [Emp:D]

Nesse sentido, podemos dizer que era esperado que a vítima tivesse tomado as providências para cessarem as agressões sofridas desde a primeira ocorrência, pois esses são os princípios que organizam esse tipo de experiência. Isso se comprova pela pergunta retórica feita por E1 (I. 138), o que pode representar uma ameaça à face de MSV1, pois a deixa em uma situação potencialmente desconfortável.

$\mathrm{Na}$ linha 141, observamos que MSV1 usou um dispositivo de menor especificidade e de menor volicionalidade, pois usa "a gente" ao invés de usar a 1a. pessoa do singular, o que demonstra maior vagueza e menor comprometimento com 0 enunciado. A expressão "a gente" agora está sendo utilizada para se referir à vítima, que, ao utilizar esse recurso de menor especificidade, indicia uma ação de preservação de face, pois fala em nome da coletividade. Além disso, revelar que "tem pena" indica uma estratégia de menor especificidade e, logo, um movimento de preservação de face, além de um forte indício de empatia pelo agressor no discurso de MSV1 (I. 141, 142).

Ademais, nas linhas 141 e 142, além do uso de dispositivos de menor especificidade ("a pessoa"), que indica uma estratégia de atenuação, há uma sobreposição de movimentos empáticos neste trecho, pois, ao mesmo tempo em que demonstra sentir empatia pelo acusado (I. 141, 142), há um marcador de elicitação de empatia, de aprovação (I. 141), cuja sugestão é de que MSV1 gostaria que E1 compreendesse seus motivos: "a gente tem pena" (I. 141).

\subsection{A interação de MSV2 com E2.}

MSV2 vai à DEAM com o objetivo de pedir ajuda à polícia para afastá-lo de sua residência. Em um primeiro momento, MSV2 mantém a face de alguém que está sendo usada, portanto, precisa da intervenção policial, sendo esse seu objetivo com a interação.

Entretanto, tão logo dá-se início o processo interacional, a face de MSV2 é ameaçada quando a E2 observa nos dados que MSV2 já havia prestado queixa anteriormente contra o ex-companheiro, sem nunca ter requerido as medidas protetivas.

\section{E2 E não quis $[E V I+]$ a medida na época [FC: $A m F]$}

10.

... quis a audiência.

11.

... teve essa audiência?

12. MSV2 teve a audiência

$13 . \quad$..né?

14.

...eu passei 3 meses [ESP+]

\section{na casa da mamãe [FC:PPF]}

15.

... enquanto ele:.:.

16.

...se organizava pra sair [Fc:

AtF] [Fc:AtFo] [Emp:D][FC:PPF]

17. E2: [Sim]

18. MSV2: [porque ele] nunca [AVA-] trabalhava de carteira assinada...

19.

...ele só fazia bico [AVA-] enquanto eu morava [com ele] [Emp: EL]

20. E2: [hum]

A escrivã lê o antigo BO que tinha sido feito pela vítima no passado e constata que não houve, na época, pedido de medida protetiva contra o excompanheiro. Nesse sentido, sua fala $(1.9,10)$, que contém um dispositivo de maior evidencialidade, representa uma ameaça à face de MSV2, pois dentro 
desse contexto discursivo, há uma expectativa por parte da polícia de que as MSV utilizem os mecanismos disponíveis de enfrentamento à violência criados a partir da implantação da Lei Maria da Penha (lei 11.340/06), logo, por não ter requerido as medidas e por ter permitido a permanência do excompanheiro em sua casa, MSV2, possivelmente, sente que sua face está sendo ameaçada.

Observamos, assim, que MSV2 fornece uma justificativa da permanência do ex-companheiro em sua casa (I. 14-16), o que nos remete a uma ação de atenuação tanto de sua própria face como da face do outro, logo, uma manifestação de preservação da própria face. Usa um modulador de maior evidencialidade (I.14) para ajudar na recuperação de sua face. Além disso, é possível verificar um indício de doação empática em relação ao companheiro em função da justificativa (I. 16).

Para desqualificar a ação do ex-companheiro, enquanto tenta preservar sua própria face, usa dispositivos de avaliatividade negativa (I. 18) ("nunca" e "bico"), para relatar que o acusado não trabalhava. Essa passagem é precedida pelo advérbio de exclusão "só" (I. 19), antecedendo à ação de "fazer bico", denotando uma avaliação negativa, que consiste em fazer pequenos trabalhos informais.

$$
\begin{aligned}
& \text { 21. MSV2: } \ldots(1.0) \text { só que o:: } \\
& \text { 22. } \ldots(2.0) \text { agora }[\mathrm{PROX}+] \text { o } \\
& \text { inferno [AVA-] continua }
\end{aligned}
$$$$
\text { ...porque:: }
$$$$
24 .
$$$$
\text { ...ele tem um barraco }
$$

[AVA-]

25. ...mas tá 24 horas [QUA+] á

dentro $[E S P+][E m p: ~ E L]$

26.

E2: aahh[Emp:R+]

27. Ele não sai de dentro

\section{$[E S P+]$ da sua $[E V I+]$ casa... $[E m p: R+]$}

28. MSV2: ele não sai [Emp: AC]

Para caracterizar negativamente a descrição da situação que está passando, MSV2 usa um dispositivo de proximidade "agora" e outro avaliativo negativo (I. 22). E após falar como se sente, ela faz uso de um dispositivo de uma oração concessiva que promove uma quebra de expectativa em relação à oração anterior ("ele tem um barraco"). Ou seja, embora tenha onde morar, ele ainda passa "24 horas" (dispositivo de maior quantificação) (I. 25), a fim de demonstrar maior intensidade, um exagero, além de corroborar seu protesto.

Verificamos que esses mecanismos usados por MSV2 indiciam uma ação de elicitação empática, cuja resposta afirmativa é verificada (I.26.27) quando a escrivã anuncia que entendeu, ao dizer a vogal a prolongadamente e ao parafrasear o que foi dito pela declarante, usando, inclusive, dois dispositivo de maior especificidade ("dentro" e "sua"), o que demonstra uma resposta favorável à elicitação de MSV2.

No segmento compreendido a seguir (I. 355360), MSV2 é questionada sobre sua decisão de pedir ou não as medidas protetivas de urgência. Na linha 355, E2 passa agora o poder de decisão à declarante e, ao fazer isso, faz uso do dispositivo emotivo de menor especificidade quando usa o verbo

\begin{tabular}{|c|c|c|}
\hline $\begin{array}{l}355 . \\
\text { vai es }\end{array}$ & $\begin{array}{l}\text { E2: } \\
\text { her fazer }\end{array}$ & a senhora é quem \\
\hline 356. & MSV2: & anhan \\
\hline 357. & E2: & aí, \\
\hline $\begin{array}{l}358 . \\
\text { falar }\end{array}$ & & ... a senhora que vai \\
\hline 359. & & $\underline{\text { se a senhora quer }}$ \\
\hline
\end{tabular}
"fazer" para referir-se ao requerimento, atenuando a impositividade do próprio nome do documento.

$$
\text { [Fc:AmF] [Fc: AmFO] }
$$
...ou se a senhora quer partir pra isso [EVI-]

$\mathrm{Na}$ linha 359, usa um dispositivo de maior quantificação ao aumentar o tom de voz quando refere a dar ao acusado uma segunda oportunidade para uma conversa, insinuando uma advertência, o que denota uma falta de empatia em relação ao 
agressor, além de ser uma ameaça à face de MSV2 e de seu ex-companheiro.

Notamos que, na linha 360, E2 faz uso de um dispositivo de menor evidencialidade ("partir pra isso") a fim de atenuar a ação de pedir medidas protetivas, o que funciona como uma forma de persuadir MSV2 a solicitá-las.

Com o ultimato, a face de MSV2 é ameaçada, pois a linha construída durante toda a interação sofre uma ofensa incidental (GOFFMAN, 2011, p. 21), de caráter não planejado, mas que ocasiona uma perda de face em MSV2 e, consequentemente, constrangimento, uma ruptura com a imagem reivindicada para si.

\section{Considerações finais}

Nesse estudo, procuramos mostrar como determinados recursos linguísticos, dispositivos emotivos da comunicação, nas falas entre duas MSV e duas escrivãs, contribuem tanto para 0 desenvolvimento de movimentos de empatia (que emergem no e pelo discurso entre as interactantes), como de elaboração de faces. Além disso, quisemos identificar quais desses recursos foram mais utilizados para regular a atenuação da fala das MSV e elicitar empatia às escrivãs.

Utilizamos a perspectiva de uma pragmática integrada para tratar tanto dos aspectos sociocognitivos, quanto das nuances intersubjetivas e emotivas nos discursos de mullheres em situação de violência, em cuja fala foi possível identificar modulações discursivas subjacentes a intenções sociocomunicativas.

Assim, as análises dos excertos da interação entre MSV1 e E2 nos mostraram que: a) diversos movimentos de atenuação foram acionados por meio, principalmente, dos dispositivos de menor evidencialidade e menor especificidade; c) esses recursos, geralmente, estão relacionados a ações de elicitação empática e de proteção de face (por parte da declarante); c) dispositivos de mais evidencialidade relacionam-se a ações de ameaça de face (oriundos das escrivãs às declarantes) e de elaboração de uma auto imagem positiva (por parte de MSV1).

$\mathrm{Na}$ análise dos 3 excertos do diálogo entre MSV2 e E2, detectamos que mecanismos de menor avaliatividade e maior quantificação também foram usados pela declarante para ameaçar a face do agressor, enquanto solicitava empatia à escrivã, a qual responde positivamente às elicitações e faz uso de alguns recursos de menor especificidade $e$ evidencialidade para persuadir MSV2 a pedir as medidas protetivas.

Nessa perspectiva, entendemos que a comunicação entre mulheres em situação de violência se constitui como um fluxo, em cujo dinamismo operam forças, tais como: intenções comunicativas das interactantes; adequação ao enquadre sociocomunicativo e ao papel social assumido; elaboração de faces e movimentos e funções de empatia.

Tais esquemas cognitivos e interpretativos, portanto, são inter-relacionados, e são constitutivos da interação, os quais, no caso deste estudo, foram investigados sob o prisma da abordagem dos dispositivos emotivos da comunicação, a qual se revelou como um frutífero aparato teóricometodológico para esse tipo de investigação.

Logo, acreditamos que a construção de conceitos que promovem a empatia no discurso é criativa e multifacetada, portanto, sendo necessário tratá-la por meio de uma abordagem mais abrangente e que trate de processos dinâmicos e mais subjetivos da construção do significado.

\section{Referências}

CAFFI, Claudia; JANNEY, Richard W. (Eds.) Involvement in language. In: Special issue of Journal of Pragmatics, 22, p. 325-373, 1994.

CAFFI, Claudia. Mitigation. Studies in Pragmatics 4, Amsterdam: Elsevier, 2007.

CAMERON, Lynne, MASLEN, Robert; LOW, S. A selective Survey of Research in Published Studies using Metaphor analysis. In: CAMERON, L.; MASLEN, R. (Eds.) Metaphor analysis: research practice in applied linguistics, social sciences and the humanities. UK: Equinox Publishing Ltd, 2010. 
DU BOIS, John W., SCHUETZE-COBURN, Stephan, CUMMING, Susanna, PAOLINO, Danae. Outline of discourse transcription. In: EDWARDS, Jane A.; LAMPERT, Martin D. (Eds) Talking data: transcription and coding in discourse research. Hillsdale, NJ: Lawrence Erlbaum, 1993. p. 45-89.

GOFFMAN, Ervin. Interaction Ritual: essays on face to face behaviours. Garden City: Anchor Doubleday, 1967.

Frame Analysis: An Essay on the Organization of Experience. Boston: Northeastern University Press, 1985.

Ritual de interação: ensaios sobre o comportamento face a face. Tradução Fábio Rodrigues Ribeiro da Silva. Petrópolis: Vozes, 2011. $255 \mathrm{p}$.

JAMISON, K. G. Movimentos de empatia no discurso da violência conjugal: uma análise linguísticocognitiva no enquadre comunicativo dos boletins de ocorrência. 2015. 289 p. Tese (doutorado) Universidade Federal do Ceará, Centro de Humanidades, Departamento de Letras Vernáculas, Programa de Pós-Graduação em Linguística, Fortaleza, 2015.

PRETI, Dino. A oralidade na escrita: o diálogo de ficção. In: PRETI, D. (Org.) Estudos de língua oral e escrita. Rio de Janeiro: Lucerna, 2004, p.117215.
MARTINOVSKI, Bilyana. Cognitive and emotive empathy in discourse. In: Proceedings of the 28th Annual Conference of the Cognitive Society, Vancouver, Canada, 2006. Disponível em: <http://csjarchive.cogsci.rpi.edu/proceedings/2006/ docs/p1783.pdf> Acesso em : 20/12/2014.

MARTINOVSKI. Bilyana; MAO, Wenji. Emotion as an argumentation engine: Modelling the role of emotion in negotiation. Journal of Group Decision and Negotiation. Vol. 18, no. 3,p. 235-259, 2009.

MENDONÇA, Ricardo F.; SIMÕES, Paula G. Enquadramento: diferentes operacionalizações de um conceito. In: Revista Brasileira de Ciências Sociais. Vol 27, n. 79, p. 187-235,Jun, 2012.

MORAND, David. Language and power: an empirical analysis of linguistic strategies used in superior subordinate communication. In: Journal of Organizational Behavior. Vol 21,n. 3, p. 235-248, 2000.

PEDROSA, Robert. De cada 10 mulheres de Teresina que denunciam agressores, sete retiram a queixa. Portal do dia Disponível em: <https://goo.gl/5xflsV>. Acesso em: 20/03/2013.

VILLAÇA, Ingedore G.; BENTES, Anna Cristina. Aspectos da Cortesia na Interação Face a Face. In: PRETI, D. (org.) Cortesia verbal: Projetos Paralelos NURC/SP. Vol. 9. São Paulo: Humanitas, 2008.

TRACY, Karen.; COUPLAND, Nancy. (Eds.) Multiple goals in discourse. Clevedon: Mutilingual Matters, 1990. 176p.

\section{COMO CITAR ESSE ARTIGO}

JAMISON, Kaline Girão. MECANISMOS DE EMOTIVIDADE EM RELATOS DE VIOLÊNCIA: ESTRATÉGIAS DE ELICITAÇÃO-EMPÁTICA E DE (RE) ENQUADRE SOCIOCOMUNICATIVO. Signo, Santa Cruz do Sul, v. 42, n. 75, dez. 2017. ISSN 1982-2014. Disponível em: <https://online.unisc.br/seer/index.php/signo/article/view/9822>. Acesso em: doi: http://dx.doi.org/10.17058/signo.v42i75.9822. 